Article

\title{
Formation and Thermal Behaviors of Ternary Silicon Oxycarbides derived from Silsesquioxane Derivatives
}

\author{
Yoshiaki Iwase $^{1,2}$, Teruaki Fuchigami ${ }^{2}$, Yoji Horie ${ }^{1}$, Yusuke Daiko ${ }^{2}$, ${ }^{\text {, Sawao Honda }}{ }^{2}$ \\ and Yuji Iwamoto $2, *$ (D) \\ 1 Applied Research Laboratory, General Center of Research and Development, Toagosei Co., Ltd., 8, \\ Showa-cho, Minato-ku, Nagoya 455-0026, Japan; yoshiaki_iwase@mail.toagosei.co.jp (Y.I.); \\ youji_horie@mail.toagosei.co.jp (Y.H.) \\ 2 Department of Life Science and Applied Chemistry, Graduate School of Engineering, Nagoya Institute of \\ Technology, Gokiso-cho, Showa-ku, Nagoya 466-8555, Japan; fuchigami.teruaki@nitech.ac.jp (T.F.); \\ daiko.yusuke@nitech.ac.jp (Y.D.); honda@nitech.ac.jp (S.H.) \\ * Correspondence: iwamoto.yuji@nitech.ac.jp
}

Received: 26 April 2019; Accepted: 21 May 2019; Published: 27 May 2019

check for updates

\begin{abstract}
Silsesquioxane (SQ) derivatives possessing intramolecular $\mathrm{H}_{2} \mathrm{C}=\mathrm{CH}$ - groups and $\mathrm{Si}-\mathrm{H}$ groups were designed as precursors for ternary silicon oxycarbide ( $\mathrm{SiOC})$. By using $\mathrm{R}-\mathrm{Si}(\mathrm{OMe})_{3}$, $\mathrm{H}-\mathrm{Si}(\mathrm{OEt})_{3}$ and $\left(\mathrm{H}-\mathrm{Si}(\mathrm{Me})_{2}\right)_{2} \mathrm{O}$ as starting compounds, SQ derivatives of VH-SQ ( $\mathrm{R}=$ vinyl) and St-H-SQ ( $\mathrm{R}=$ stylyl) were successfully synthesized through the conventional sol-gel route. Simultaneous thermogravimetric and mass spectroscopic analyses up to $1000{ }^{\circ} \mathrm{C}$ revealed that in situ cross-linking via hydrosilylation and demethanation of VH-SQ suppressed the evolution of gaseous hydrocarbon species to afford amorphous SiOC having a composition close to the desired stoichiometric $\mathrm{SiO}_{2(1-x)} \mathrm{C}_{\mathrm{x}}(\mathrm{x}=$ ca. 0.3$)$ with a high yield. The effect of carbon content on the phase separation and crystallization of the SQ-derived amorphous SiOC was studied by several spectroscopic analyses and TEM observation. The results were discussed aiming to develop a novel polymer-derived ceramics (PDCs) route for in situ formation of binary $\beta$-SiC-amorphous $\mathrm{SiO}_{2}$ nanocomposites with enhanced thermal and mechanical stability.
\end{abstract}

Keywords: silicon oxycarbide; amorphous state; thermal stability; crystallization; silsesquioxane; Polymer-Derived Ceramics (PDCs)

\section{Introduction}

Recently, increasing attention has been directed to organic-inorganic hybrid materials as promising functional materials in diverse fields such as optics, electronics, housing and energy. Synergistic properties of hybrid materials can be achieved by harmonizing advantageous properties of an organic component, such as solubility, plasticity and hydrophobicity, with those of an inorganic component, namely, mechanical strength and thermal and chemical stability [1,2]. Silsesquioxane (SQ) derivatives (Figure 1) are typical organic-inorganic hybrid materials that have been widely known as commercial products, including hard coatings, protective coatings for spacecraft and gate insulating films, with each required property which tuned by modifying its composition at the molecular scale level [3-6]. 

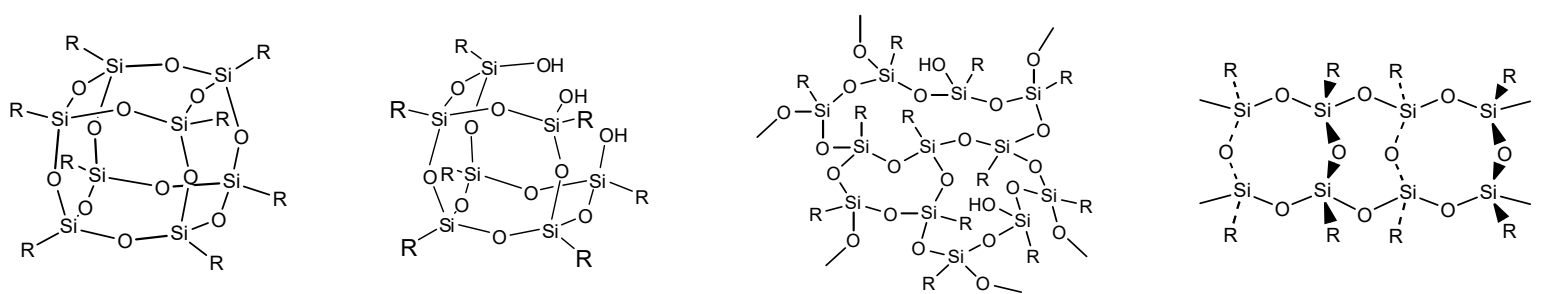

Figure 1. General structures of silsesquioxanes (SQs).

Silsesquioxane derivatives have been also found as a useful polymer precursor for ternary silicon oxycarbides (SiOC) composed of an amorphous network of corner-connected $\mathrm{SiO}_{\mathrm{x}} \mathrm{C}_{4-\mathrm{x}}$ $(x=0-4)$ tetrahedral [7]. The chemical composition of polymer-derived SiOC materials can be tuned by incorporating appropriate organic substituents and controlling cross-linking degrees of polymer precursors prior to pyrolysis under inert atmosphere. Typically, carbon-rich silicon oxycarbides have been synthesized [7-9]. They exhibit an excellent thermal stability in terms of keeping amorphous states beyond $1000{ }^{\circ} \mathrm{C}$ [9]. At around $1200-1400{ }^{\circ} \mathrm{C}$, amorphous SiOC begins to start phase separation and crystallization. One possible pathway is the formation of amorphous $\mathrm{SiO}_{2}$, $\beta-\mathrm{SiC}$ and amorphous/graphitic carbon without the evolution of any gaseous products (Equation (1)). Then, further crystallization of $\beta-\mathrm{SiC}$ proceeds via a decomposition reaction between $\mathrm{SiO}_{2}$ and carbon, according to Equation (2). Finally, the decomposition completes to afford a stoichiometric mixture of amorphous $\mathrm{SiO}_{2}$ and $\beta-\mathrm{SiC}$ (Equation (3)) [9-12].

$$
\begin{gathered}
\text { Amorphous } \mathrm{SiOC} \rightarrow \mathrm{SiO}_{2}(\mathrm{a})+\mathrm{xSiC}(\beta)+\mathrm{yC}(\mathrm{a} / \text { gra }) \\
\mathrm{SiO}_{2}(\mathrm{a})+3 \mathrm{C} \rightarrow \mathrm{SiC}(\beta)+2 \mathrm{CO}(\mathrm{g}) \uparrow \\
\mathrm{SiO}_{2}(\mathrm{a})+\mathrm{xSiC}(\beta)+\mathrm{yC}(\mathrm{a} / \mathrm{gra}) \rightarrow(1-\mathrm{y} / 3) \mathrm{SiO}_{2}(\mathrm{a})+(\mathrm{x}+\mathrm{y} / 3) \mathrm{SiC}(\beta)+2 / 3 \mathrm{CO}(\mathrm{g}) \uparrow
\end{gathered}
$$

Saha and Raj proposed a practical method for predicting the maximum crystallization and weight loss for amorphous $\mathrm{SiOC}$ materials located within the $\mathrm{SiC}-\mathrm{K}-\mathrm{SiO}_{2}$ triangle shown in the $\mathrm{Si}-\mathrm{O}-\mathrm{C}$ composition diagram (Figure 2), and it was reported that the thermal behavior in terms of $\beta$-SiC crystallization and $\mathrm{CO}$ evolution up to $1350{ }^{\circ} \mathrm{C}$ of the polymer-derived amorphous $\mathrm{SiO}_{1.0} \mathrm{C}_{1.6}$, labeled as (A) in Figure 2, was well consistent with their prediction [9].

For improving the thermal and mechanical stability of $\mathrm{SiC}$-amorphous $\mathrm{SiO}_{2}$ composites, it is attractive to synthesize amorphous $\mathrm{SiOC}$ with a stoichiometric composition $\left(\mathrm{SiO}_{2(1-x)} \mathrm{C}_{\mathrm{x}}\right)$ located on the tie line between $\mathrm{SiC}$ and $\mathrm{SiO}_{2}$ to afford a segregated carbon-free $\mathrm{SiC}-\mathrm{SiO}_{2}$ composite (according to Equation (1) without excess carbon). Heat treatment at $1400{ }^{\circ} \mathrm{C}$ of amorphous $\mathrm{SiO}_{1.5} \mathrm{C}_{0.31}$ possessed a composition with relatively low carbon content and was close to the $\mathrm{SiC}-\mathrm{SiO}_{2}$ tie line (labeled as (B) in Figure 2), resulting in the formation of binary $\beta$-SiC nanocrystallites finely dispersed amorphous $\mathrm{SiO}_{2}$ [10]. By hot-pressing at $1400{ }^{\circ} \mathrm{C}$, amorphous $\mathrm{SiO}_{1.5} \mathrm{C}_{0.30}$ (labeled as (C) in Figure 2) was also converted to such a segregated carbon-free nanocomposite, which exhibited a relatively low coefficient of thermal expansion (ca. $3.2 \times 10^{-6} \mathrm{~K}^{-1}$ ), low thermal conductivity (ca. $1.5 \mathrm{~W} \cdot \mathrm{m}^{-1} \cdot \mathrm{K}^{-1}$ ) and high viscosity approximately two orders of magnitude higher than that of vitreous silica [11,12].

In this study, amorphous $\mathrm{SiO}_{2(1-x)} \mathrm{C}_{\mathrm{x}}$ with a relatively high carbon content (labeled as $\mathrm{S} 1$ in Figure 2)-approximately two times higher compared with those of the previous (B) and (C) in Figure 2-was synthesized together with a reference material of carbon-rich SiOC (labeled as S2 in Figure 2 comparable with (A) in Figure 2 previously investigated by Saha and Raj [9]. 


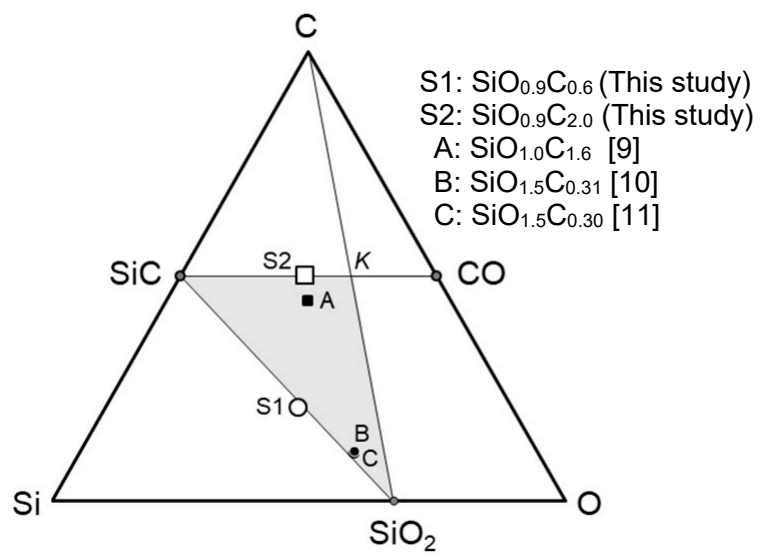

Figure 2. Chemical compositions of the polymer-derived amorphous SiOC reported in literature [9-11], and those of the S1 and S2 derived from SQs synthesized through the sol-gel route shown in Equation (4).

For the synthesis of S1 and S2, silsesquioxane (SQ) derivatives which have intramolecular $\mathrm{H}_{2} \mathrm{C}=\mathrm{CH}$ - groups and Si-H groups labeled as VH-SQ and St-H-SQ were designed respectively, and synthesized through the conventional sol-gel route (Equation (4)). The thermal decomposition of organic substituents, as well as the thermally induced in situ cross-linking during pyrolysis of the SQ derivatives, were characterized. Then, phase separation and crystallization of the SQ-derived amorphous SiOC were studied and discussed, with the intention of developing a novel polymer-derived ceramic (PDC) route for the in situ formation of binary $\beta$-SiC-amorphous $\mathrm{SiO}_{2}$ nanocomposites.

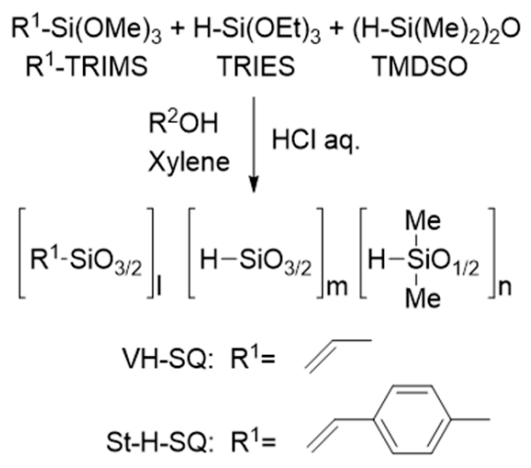

\section{Experimental Section}

\subsection{Precursor Synthesis}

The handling of all the reagents and products in this study was performed under inert atmosphere of pure nitrogen $\left(\mathrm{N}_{2}\right)$. VH-SQ and St-H-SQ were synthesized through the sol-gel route (Equation (4)) according to the procedures described in the patents released from Toagosei Co., Ltd. [6]. A 500-mL four-necked flask equipped with a dropping funnel, a magnetic stirrer and a septum, was charged with vinyl-trimethoxysilane (V-TRIMS, $10.4 \mathrm{~g}, 70 \mathrm{mmol}$, TCI, Tokyo, Japan), triethoxysilane (TRIES, $34.5 \mathrm{~g}$, $210 \mathrm{mmol}$, Toagosei Co. Ltd., Tokyo, Japan), tetramethyldisiloxane (TMDSO, $9.38 \mathrm{~g}$, $70 \mathrm{mmol}$, TCI, Tokyo, Japan), 2-propanol (40 g, Wako Pure Chemical Industry Ltd., Osaka, Japan) and xylene (120 g, TCI, Tokyo, Japan). Through the funnel, the mixture of aqueous $\mathrm{HCl}$ (diluted to $1.28 \%, 16.5 \mathrm{~g}$, Kishida Chemical Co. Ltd., Osaka, Japan) and 2-propanol (20 g) was added dropwise at $20^{\circ} \mathrm{C}$ over $30 \mathrm{~min}$. The mixture was allowed to stand overnight at around $25^{\circ} \mathrm{C}$. Then, the solvent was removed under vacuum below $60^{\circ} \mathrm{C}$ to afford VH-SQ as a colorless paste ( $20.5 \mathrm{~g}, 96 \%$ yield).

By using stylyl-trimethoxysilane (St-TRIMS, $31.4 \mathrm{~g}, 140 \mathrm{mmol}$, TCI, Tokyo, Japan) instead of V-TRIMS, St-H-SQ was synthesized under the same manner (colorless solid, $27.5 \mathrm{~g}$, 92\% yield). 


\subsection{Pyrolysis and Heat Treatment}

The synthesized SQ was placed in an alumina boat and pyrolyzed in a quartz tube furnace under flowing nitrogen $\left(\mathrm{N}_{2}, 200 \mathrm{~mL} / \mathrm{min}\right)$ by heating from room temperature to $800^{\circ} \mathrm{C}$ in $2 \mathrm{~h}$, then maintaining for an additional $1 \mathrm{~h}$ and finally furnace-cooling down to room temperature to create a solid product. to afford a product as a solid.

The pyrolyzed sample was ground to a fine powder using mortar and pestle. The powdered sample was placed on a carbon crucible and heat-treated in a graphite resistance-heated furnace (Model High Multi 5000, Fujidempa Kogyo, Osaka, Japan) under vacuum from room temperature to $500^{\circ} \mathrm{C}$. Then, Ar gas was introduced into the furnace at $500^{\circ} \mathrm{C}$ and the temperature was increased to 1400 , 1600 or $1800{ }^{\circ} \mathrm{C}$ and held for an additional $1 \mathrm{~h}$. The heating rate was $10^{\circ} \mathrm{C} / \mathrm{min}$. The Ar pressure applied in this heat treatment from 500 to $1800{ }^{\circ} \mathrm{C}$ was $98 \mathrm{kPa}$. After the heat treatment, the sample was cooled down to room temperature in the furnace.

\subsection{Characterizations}

The attenuated total reflection-infra red (ATR-IR) spectra were recorded on as-synthesized SQs with a diamond prism under an incidence angle of $45^{\circ}$ (Model Spectrum 100, Perkin Elmer, Waltham, MA, USA).

${ }^{29} \mathrm{Si}$ nuclear magnetic resonance (NMR) spectra were acquired at 79.5 MHz (Model ECA-400, JEOL, Tokyo, Japan). The spectra for as-synthesized SQs were recorded in $\mathrm{CDCl}_{3}$ solution at room temperature, and the chemical shifts were referenced to tetramethylsilane $(0 \mathrm{ppm})$. For pyrolyzed and heat-treated samples, solid-state ${ }^{29}$ Si magic angle spinning (MAS) NMR spectra were acquired at a rotation frequency of $15 \mathrm{kHz}$, and the chemical shifts were quoted relative to the signals of 3-(trimethylsilyl) propionic acid sodium salt (2 ppm).

Thermal behaviors up to $1000^{\circ} \mathrm{C}$ were studied by simultaneous thermogravimetric (TG) and mass spectroscopic (MS) analyses (Model TG/DTA 6300, Hitachi High Technologies Ltd., Tokyo, Japan/Model JMS-Q1050GC, JEOL, Tokyo, Japan). The measurements were performed under flowing helium $(100 \mathrm{~mL} / \mathrm{min})$ with a heating rate of $20^{\circ} \mathrm{C} / \mathrm{min}$. Conventional thermogravimetric and differential thermal analyses (TG/DTA) analyses were also performed in $\mathrm{N}_{2}$ to study their exothermal behaviors.

Elemental analyses were performed on the pyrolyzed or heat-treated samples for oxygen, nitrogen and hydrogen (inert-gas fusion method, Model EMGA-930, HORIBA Ltd., Kyoto, Japan), and carbon (non-dispersive infrared method, Model CS844, LECO Co., St Joseph, MI, USA). The silicon content in the samples was calculated as the difference of the sum of the measured $\mathrm{C}, \mathrm{N}, \mathrm{O}$ and $\mathrm{H}$ content to $100 \mathrm{wt} \%$.

X-ray diffraction (XRD) measurements were performed on pyrolyzed or heat-treated samples (Model X'pert Pro $\alpha 1$, Philips Ltd., Amsterdam, Nederland).

Raman spectra were recorded on the pyrolyzed or heat-treated samples (Model NRS-3300, Jasco, Tokyo, Japan) using a 532-nm solid laser.

Crystallization behavior of the polymer-derived amorphous SiOC materials was observed by using a transmission electron microscope (TEM, Model JEM-2100F, JEOL, Tokyo, Japan, operating at $200 \mathrm{kV}$ ). Analytical investigations were carried out by electron energy loss spectroscopy (EELS, Model Enfina, Gatan, Inc., Pleasanton, CA, USA).

\section{Results and Discussion}

\subsection{SQ Preceramic Polymers}

The chemical structures of VH-SQ and St-H-SQ were identified by the ATR-IR and ${ }^{29} \mathrm{Si}$ NMR spectra shown in Figures 3 and 4, respectively.

ATR-IR spectra for as-synthesized SQs presented characteristic absorption bands at 2136 and $2252 \mathrm{~cm}^{-1}$ assigned to Si-H derived from TMDSO and TRIES, respectively, with those at 1392 and $1602 \mathrm{~cm}^{-1}$ attributed to the $\mathrm{C}=\mathrm{C}$ bond (Figure $3 \mathrm{a}, \mathrm{b}$ ). The intensity of the broad peak at around 
$3376 \mathrm{~cm}^{-1}$ indicated in St-H-SQ (Figure 3b) was relatively higher than that in VH-SQ (Figure 3a). This could be due to the contribution of C-H stretching in phenyl moiety of the styryl group. On the other hand, the broad band at around 3300 to $3700 \mathrm{~cm}^{-1}$ was assigned to the Si-OH group (Figure $3 \mathrm{~b}$ ).

The ${ }^{29} \mathrm{Si}$ NMR spectrum for VH-SQ presented characteristic peaks attributed to the units composing the ternary SiOC organic-inorganic hybrid network at $-3.3,-79.5$ to -81.1 , and -86.0 ppm, assigned to $\mathrm{M} 1\left(\mathrm{O}-\mathrm{Si}\left(\mathrm{CH}_{3}\right)_{2} \mathrm{H}\right), \mathrm{T}^{\mathrm{Vi}}\left((\equiv \mathrm{SiO})_{3} \mathrm{Si}-\mathrm{Vi}\right)$ and $\mathrm{T}^{\mathrm{H}}\left((\equiv \mathrm{SiO})_{3} \mathrm{Si}-\mathrm{H}\right)$, respectively [13]. Note that another very wide and weak peak centered at around -110 ppm was the background (i.e., Q4 (Si (OSi $\left.)_{4}\right)$ unit derived from the glass sample tube (Figure 4a). In addition to these peaks, St-H-SQ presented a broad peak centered at $-68.8 \mathrm{ppm}$ assigned to the $\mathrm{T} 2^{\mathrm{St}}\left((\equiv \mathrm{SiO})_{2}(\mathrm{MeO})_{2} \mathrm{Si}-\mathrm{St}\right)$ unit [13] (Figure $\left.4 \mathrm{~b}\right)$. However, compared with $\mathrm{VH}-\mathrm{SQ}$, the relative peak intensity of the M1 unit at $-2.9 \mathrm{ppm}$ was apparently lower. This feature suggests that the number of the terminate M1 units of St-H-SQ was smaller than that of VH-SQ, which could lead to the detection of $(\equiv \mathrm{SiO})_{3} \mathrm{Si}-\mathrm{OH}$ by the ATR-IR spectroscopic analysis (Figure 4b).
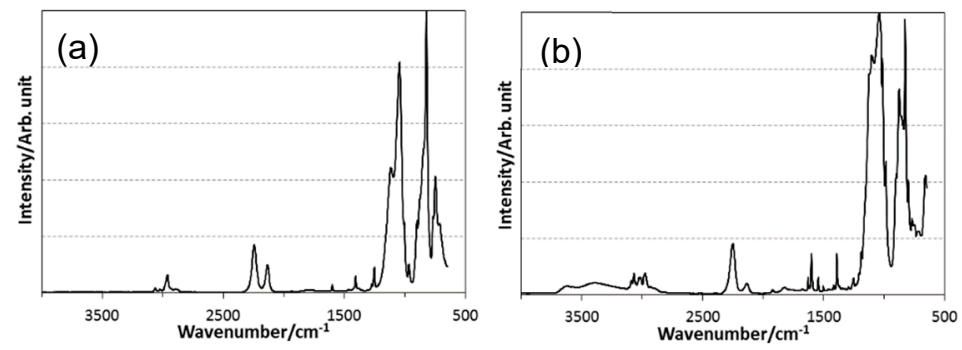

Figure 3. ATR-IR spectra for (a) VH-SQ and (b) St-H-SQ.


Figure 4. ${ }^{29} \mathrm{Si}$ NMR spectra for (a) VH-SQ and (b) St-H-SQ.

These results revealed that VH-SQ and St-H-SQ had possessing a common main architecture with different compositions that was successfully synthesized as designed. Since the residual OR and Si-OH groups were easily eliminated during pyrolysis up to $800^{\circ} \mathrm{C}$, the SQ derivatives synthesized in this study were converted to inorganic SiOC without further purification

\subsection{Pyrolytic Behavior}

The SQ derivatives showed high ceramic yields at $1000{ }^{\circ} \mathrm{C}$, and $82 \%$ and $88 \%$ were achieved for VH-SQ and St-H-SQ, respectively. Each of them exhibited a DTA curve with a broad exothermic peak at around 200 to $600{ }^{\circ} \mathrm{C}$ (Figure 5A1,B1). Figure 6 shows the typical results obtained for VH-SQ. According to the ATR-IR spectroscopic analysis, the band intensities of 2136 and $2252 \mathrm{~cm}^{-1}$ which assigned to $\mathrm{Si}-\mathrm{H}$ groups of SQ derivatives remarkably decreased in this temperature range. Thus the broad exothermic peak could be attributed mainly to hydrosilylation (Figure 5A1,B1).

VH-SQ presented two weight-loss regions, $10 \%$ up to $300{ }^{\circ} \mathrm{C}$ and $8 \%$ at around $400-800{ }^{\circ} \mathrm{C}$ (Figure 5A1). The gas evolution was mainly detected at the first weight-loss region (Figure 5A2), and several gaseous species were simultaneously detected (Figure 5A3). The m/z ratio at 18 could be assigned to $\mathrm{H}_{2} \mathrm{O}^{+}$formed by the dehydration condensation between the Si-OH groups. Another 
element with the $\mathrm{m} / \mathrm{z}$ ratio at 28 was assigned to $\mathrm{C}_{2} \mathrm{H}_{4}{ }^{+}$as a fragment of the organic group formed by the hydrosilylation. On the other hand, the $\mathrm{m} / \mathrm{z}$ ratio at 91 was a fragment of xylene (i.e., residual solvent). Those at 59 and 45 could also be fragments that originated from another residual solvent, 2-propanol. However, it should be noted that the $\mathrm{m} / \mathrm{z}$ ratio at 59 , detected at around $400{ }^{\circ} \mathrm{C}$, could be assigned another possible element, $\mathrm{C}_{2} \mathrm{H}_{7} \mathrm{Si}^{+}\left(\mathrm{HMe}_{2} \mathrm{Si}^{+}\right)$, formed in situ by the thermal decomposition of the TMDSO unit. The $\mathrm{m} / \mathrm{z}$ ratio at 16 , detected at around $400-800{ }^{\circ} \mathrm{C}$, was assigned to $\mathrm{CH}_{4}{ }^{+}$evolved by the demethanation between the $\mathrm{Si}-\mathrm{CH}_{3}$ groups. Accordingly, the first weight loss up to $300{ }^{\circ} \mathrm{C}$ was due to the evaporation of the residual solvents and $\mathrm{H}_{2} \mathrm{O}$, while the cross-linking through the hydrosilylation and demethanation efficiently proceeded up to $800^{\circ} \mathrm{C}$, which led to the high ceramic yield at $1000{ }^{\circ} \mathrm{C}$.

In the case of St-H-SQ, the main gas evolution shifted to higher temperatures ranging from 450 to $650{ }^{\circ} \mathrm{C}$, and the cross-linking via demethanation was found to proceed at 450 to $800^{\circ} \mathrm{C}$ by detecting $\mathrm{CH}_{4}{ }^{+}(\mathrm{m} / \mathrm{z}=16)$. Other gas species with $\mathrm{m} / \mathrm{z}$ ratios at $91\left(\mathrm{CH}_{2}-\mathrm{C}_{6} \mathrm{H}_{5}{ }^{+}\right)$and $78\left(\mathrm{C}_{6} \mathrm{H}_{6}{ }^{+}\right)$that evolved above $450{ }^{\circ} \mathrm{C}$ were fragments of the organic group formed by hydrosilylation, while that at $27\left(\mathrm{C}_{2} \mathrm{H}_{3}{ }^{+}\right)$ could have originated from the remaining vinyl group (Figure 5B2,3).
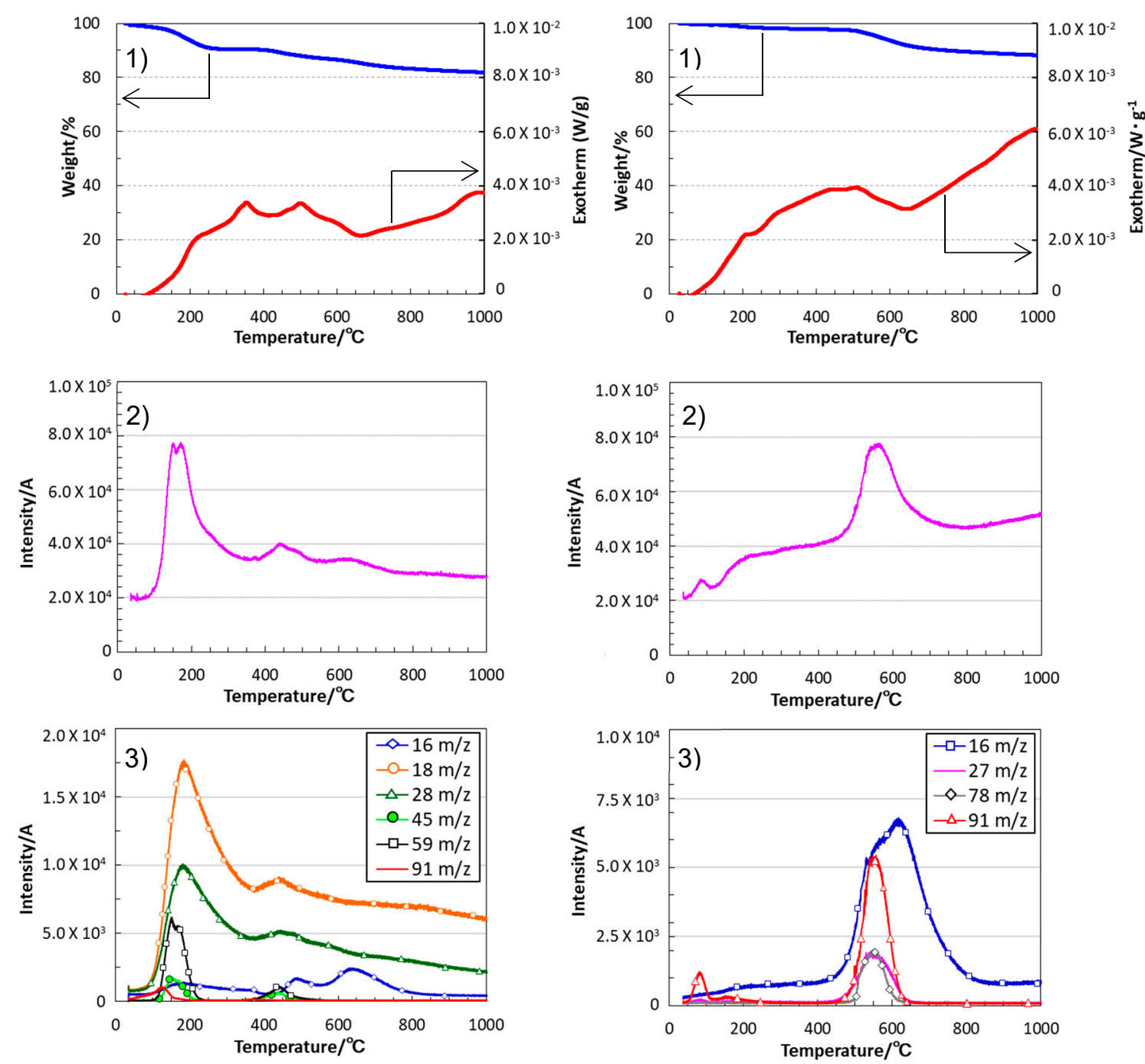

(A)

(B)

Figure 5. Thermal behavior of (A) VH-SQ and (B) St-H-SQ under a He flow. (1) TG/DTA curves, (2) total ion current chromatogram (TICC) detected for the gaseous species formed in situ, and (3) continuous in situ monitoring of the evolved gaseous species by mass spectroscopy. 


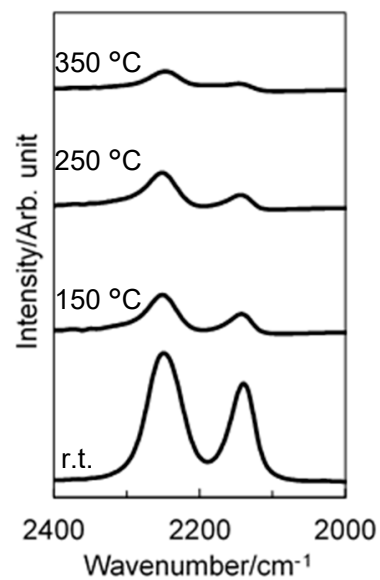

Figure 6. ATR-IR spectra for as-synthesized VH-SQ (room temperature) and those after heat treatment at 150 to $350{ }^{\circ} \mathrm{C}$ in $\mathrm{N}_{2}$.

Chemical compositions of the $800^{\circ} \mathrm{C}$-pyrolyzed products are listed in Table 1. As reference data, theoretical compositions of as-synthesized SQ derivatives are also listed in this table. Besides high ceramic yield, the in situ cross-linking of VH-SQ led to suppressing the thermal decomposition of organic groups, which lead to the formation of inorganic SiOC with the desired carbon content, labeled as S1. Moreover, by replacing the vinyl group with the styryl group in the SQ, the amount of carbon in the SiOC successfully increased to afford S2.

Table 1. Chemical composition of pyrolyzed and heat-treated samples.

\begin{tabular}{|c|c|c|c|c|c|}
\hline \multirow{2}{*}{ Sample } & \multicolumn{4}{|c|}{ Composition $[w t \%]$} & \multirow{2}{*}{$\begin{array}{c}\text { SiOC Composition } \\
\text { Empirical Ratio } \mathrm{SiO}_{2(1-x)} \mathrm{C}_{\mathrm{x}}+\mathrm{y} \mathrm{C}_{\text {free }} \text { or } \mathrm{ySi}_{\text {free }}\end{array}$} \\
\hline & Si & $\mathbf{O}$ & $\mathrm{C}$ & $\mathbf{H}$ & \\
\hline As-synthesize & 45.9 & 34.1 & 15.7 & 4.26 & $\mathrm{SiO}_{1.3} \mathrm{C}_{0.8} \mathrm{H}_{2.6} \quad\left(\mathrm{SiO}_{1.3} \mathrm{C}_{0.35}+0.45 \mathrm{C}_{\text {free }}\right)$ \\
\hline S1: $800{ }^{\circ} \mathrm{C}$-pyrolyzed VH-SQ & 57.4 & 28.9 & 12.8 & 0.94 & $\mathrm{SiO}_{0.9} \mathrm{C}_{0.5} \mathrm{H}_{0.5} \quad\left(\mathrm{SiO}_{0.9} \mathrm{C}_{0.53}+0.05 \mathrm{Si}_{\text {free }}\right)$ \\
\hline S1: $1400^{\circ} \mathrm{C}$-heat treated & 55.4 & 29.5 & 15.1 & 0.08 & $\mathrm{SiO}_{0.9} \mathrm{C}_{0.6} \mathrm{H}_{0.0} \quad \mathrm{SiO}_{0.9} \mathrm{C}_{0.55}+0.05 \mathrm{C}_{\text {free }}$ \\
\hline S1: $1600^{\circ} \mathrm{C}$-heat treated & 55.4 & 30.6 & 15.1 & 0.03 & $\mathrm{SiO}_{1.0} \mathrm{C}_{0.7} \mathrm{H}_{0.0} \quad \mathrm{SiO}_{0.9} \mathrm{C}_{0.50}+0.2 \mathrm{C}_{\text {free }}$ \\
\hline S1: $1800^{\circ} \mathrm{C}$-heat treated & 55.4 & 0.24 & 29.7 & 0.02 & $\mathrm{SiC}_{1.0} \mathrm{O}_{0.0} \mathrm{H}_{0.0} \quad \mathrm{SiC}$ \\
\hline As-synthesized St-H-SQ & 27.8 & 23.0 & 45.2 & 4.06 & $\mathrm{SiO}_{1.5} \mathrm{C}_{3.8} \mathrm{H}_{4.1} \quad\left(\mathrm{SiO}_{1.5} \mathrm{C}_{0.25}+3.55 \mathrm{C}_{\text {free }}\right)$ \\
\hline S2: $800{ }^{\circ} \mathrm{C}$-pyrolyzed St-H-SQ & 41.5 & 22.4 & 34.9 & 1.15 & $\mathrm{SiO}_{0.9} \mathrm{C}_{2.0} \mathrm{H}_{0.8} \quad\left(\mathrm{SiO}_{0.9} \mathrm{C}_{0.55}+1.45 \mathrm{C}_{\text {free }}\right)$ \\
\hline S2: $1400^{\circ} \mathrm{C}$-heat treated & 33.4 & 21.2 & 45.4 & 0.13 & $\mathrm{SiO}_{1.1} \mathrm{C}_{3.2} \mathrm{H}_{0.1} \quad \mathrm{SiO}_{1.1} \mathrm{C}_{0.45}+2.75 \mathrm{C}_{\text {free }}$ \\
\hline S2: $1600^{\circ} \mathrm{C}$-heat treated & 51.1 & 2.28 & 46.6 & 0.23 & $\mathrm{SiO}_{0.1} \mathrm{C}_{2.1} \mathrm{H}_{0.1} \quad \mathrm{SiO}_{1.0} \mathrm{C}_{0.95}+1.15 \mathrm{C}_{\text {free }}$ \\
\hline S2: $1800^{\circ} \mathrm{C}$-heat treated & 52.5 & 0.28 & 47.2 & 0.04 & $\mathrm{SiO}_{0.0} \mathrm{C}_{2.1} \mathrm{H}_{0.0} \quad \mathrm{SiC}+1.10 \mathrm{C}_{\text {free }}$ \\
\hline
\end{tabular}

\subsection{Crystallization Behaviors of SQ-Derived Amorphous SiOC}

As shown in Figure 7, S1 and S2 were X-ray amorphous. During heat treatment, they began to show diffraction peaks that increased in intensity with increasing temperature. Finally, the $1800{ }^{\circ} \mathrm{C}$ heat-treated samples exhibited distinct diffraction peaks at $2 \theta$ (degrees) of 35.8, 41.5, 60.0, 71.9 and 75.8, indexed to (111), (200), (211), (311) and (222) of $\beta$-SiC (JCPDS Card No. 29-1129), respectively. The weaker peak at 33.7 could be attributed to the stacking fault of $\beta$-SiC. The $\beta$-SiC crystallization onset temperatures of S1 and S2 were observed above and below $1400^{\circ} \mathrm{C}$, respectively. Then, TEM analysis was performed on the heat-treated S1 samples. As shown in Figure 8a, the $1400^{\circ} \mathrm{C}$-heated $\mathrm{S} 1$ exhibited a futureless structure typical for amorphous compounds. Then, after the $1600^{\circ} \mathrm{C}$ heat treatment, some crystallites several nanometers in size were observed within the amorphous matrix. The inter planer spacing observed for the nanocrystallite formed in situ was measured to be $0.254 \mathrm{~nm}$, which corresponded to the (111) plane of $\beta$-SiC (JCPDS card no. 29-1129) (Figure 8b). Accordingly, the $\mathrm{S} 1$ kept the amorphous state up to $1400^{\circ} \mathrm{C}$, and the $\beta$-SiC crystallization onset temperature was found to be higher than that of S2. 

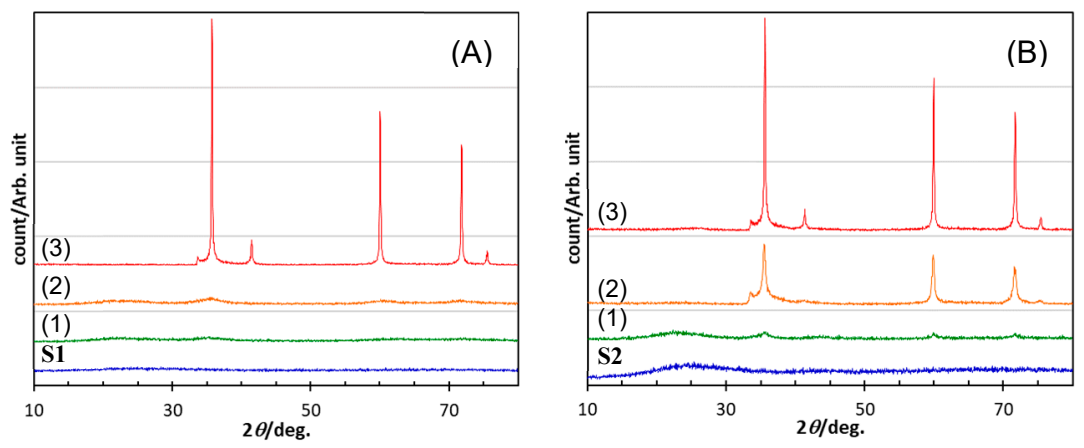

Figure 7. XRD patterns of $\mathrm{S} 1$ and $\mathrm{S} 2$ synthesized by pyrolysis at $800{ }^{\circ} \mathrm{C}$, and those after heat treatment at (1) 1400, (2) 1600 and (3) $1800{ }^{\circ} \mathrm{C}$. Polymeric precursors: (A) VH-SQ and (B) St-H-SQ.


Figure 8. TEM images of the VH-SQ-derived S1 after heat treatment at (a) 1400 and (b) $1600{ }^{\circ} \mathrm{C}$.

To study the $\beta$-SiC crystallization behavior in more details, EELS analysis was performed on the heat-treated S1 (Figure 9). After heat treatment at $1400{ }^{\circ} \mathrm{C}$, the $\mathrm{Si} \mathrm{L}_{2,3}$ edge exhibited a featureless line, then at $1600{ }^{\circ} \mathrm{C}$ the spectrum presented characteristic peaks at about 108 and $114 \mathrm{eV}$, related to $2 \mathrm{p}-\mathrm{p}^{*}$ and $2 \mathrm{p}-\mathrm{d}^{*}$ transitions in $\mathrm{SiO}_{2}[14,15]$. It is noteworthy that the distinct peak at around $110 \mathrm{eV}$ suggested that some Si bonded to both $\mathrm{O}$ and $\mathrm{C}$ partly remained [15]. On the other hand, after heat treatment at $1400{ }^{\circ} \mathrm{C}$, the $\mathrm{C}$ K-edge showed the spectrum typical for amorphous carbon (i.e., two peaks due to the $1 \mathrm{~s}-\pi^{*}(285.6 \mathrm{eV})$ and $1 \mathrm{~s}-\sigma^{*}(293 \mathrm{eV})$ transitions, respectively [16]). Then, at $1600{ }^{\circ} \mathrm{C}$, the two peaks remarkably decreased in intensity. These results suggest that phase separation to amorphous/graphitic carbon and amorphous $\mathrm{SiO}_{2}$ dominantly proceeded prior to $\beta$-SiC crystallization. This behavior is supported by the results obtained by Raman, as well as by ${ }^{29} \mathrm{Si}$ MAS NMR spectroscopic analyses. The Raman spectra for the heat-treated S1 samples (Figure 10A) indicated the formation of amorphous/graphitic carbon at 1400 and $1600{ }^{\circ} \mathrm{C}$ by detecting two distinct peaks at 1347.5 and $1596.5 \mathrm{~cm}^{-1}$, which were attributed to the D-band (for disordered graphite) and G-band (for the sp ${ }^{2}$ graphite network), respectively [17,18]. Two minor broad peaks centered at 2682.5 and $2933.5 \mathrm{~cm}^{-1}$ were attributed to the disordered carbon, assigned to the two-dimensional (2D) band and the $\mathrm{D}+\mathrm{G}$ band, respectively [17]. At $1800^{\circ} \mathrm{C}$, the peaks attributed to the amorphous/graphitic carbon almost disappeared and new peaks appeared at 797.5 and $972 \mathrm{~cm}^{-1}$ (weak), which were typical for $\beta-\mathrm{SiC}$ and corresponded to the transverse (TO) and longitudinal (LO) optical modes, respectively [19].

The ${ }^{29} \mathrm{Si}$ MAS NMR spectrum for as-synthesized S1 presented three broad peaks centered at about $-30,-70$ and -105 ppm and assigned to $\mathrm{SiO}_{2} \mathrm{C}_{2}, \mathrm{SiO}_{3} \mathrm{C}$ and $\mathrm{SiO}_{4}$ units, respectively $[20,21]$. At $1400{ }^{\circ} \mathrm{C}$, the broad peak assigned to the $\mathrm{SiO}_{4}$ units remained, while the peaks due to the mixed tetrahedral $\mathrm{SiO}_{2-\mathrm{x}} \mathrm{C}_{\mathrm{x}}(\mathrm{x}=1,2)$ units disappeared, and a new broad peak appeared at about-EELS15 ppm attributed to the $\mathrm{SiC}_{4}$ unit, which was typical for disordered $\mathrm{SiC}$ [22]. At $1600{ }^{\circ} \mathrm{C}$, another new peak appeared at about $18 \mathrm{ppm}$, which indicated the formation of $\mathrm{SiC}$ with improved crystallinity as a $\beta$ phase [22]. At $1800^{\circ} \mathrm{C}$, the spectrum presented one distinct peak attributed to $\beta$-SiC (Figure 10A3). 
Raman, as well as the ${ }^{29} \mathrm{Si}$ MAS NMR spectroscopic analyses for heat-treated S2 samples, revealed similar phase separation and subsequent $\beta$-SiC crystallization (Figures $10 \mathrm{~B}$ and 11B). However, the amorphous/graphitic carbon segregation had already started during pyrolysis up to $800{ }^{\circ} \mathrm{C}$, and remained at all temperatures from 1400 to $1800{ }^{\circ} \mathrm{C}$.

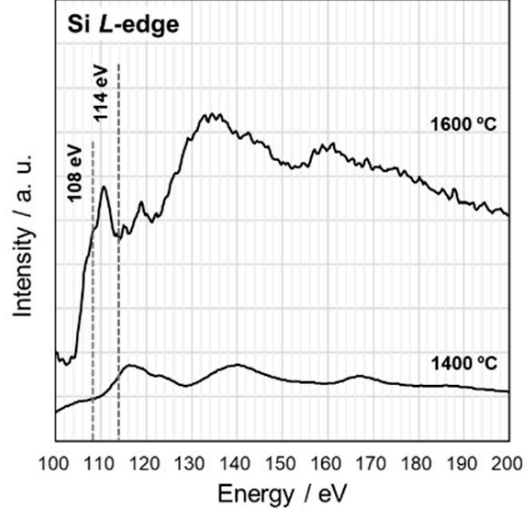

(a)

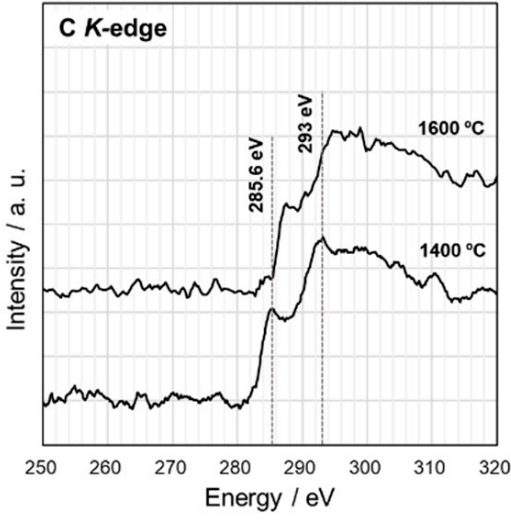

(b)

Figure 9. EELS spectra for the SQ-derived S1 after heat treatment at 1400 and $1600{ }^{\circ} \mathrm{C}$. (a) Si L-edge and (b) C K-edge.
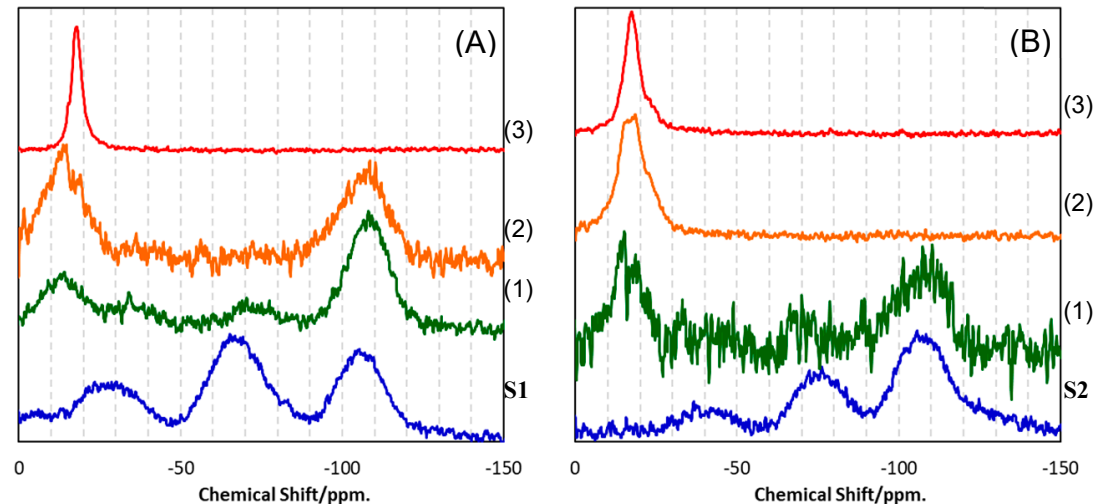

Figure 10. ${ }^{29} \mathrm{Si}$ MAS NMR spectra for SQ-derived S1 and S2 synthesized by pyrolysis at $800{ }^{\circ} \mathrm{C}$, and those after subsequent heat treatment at (1) 1400, (2) 1600 and (3) $1800{ }^{\circ} \mathrm{C}$. Polymeric precursors: (A) VH-SQ and (B) St-H-SQ.
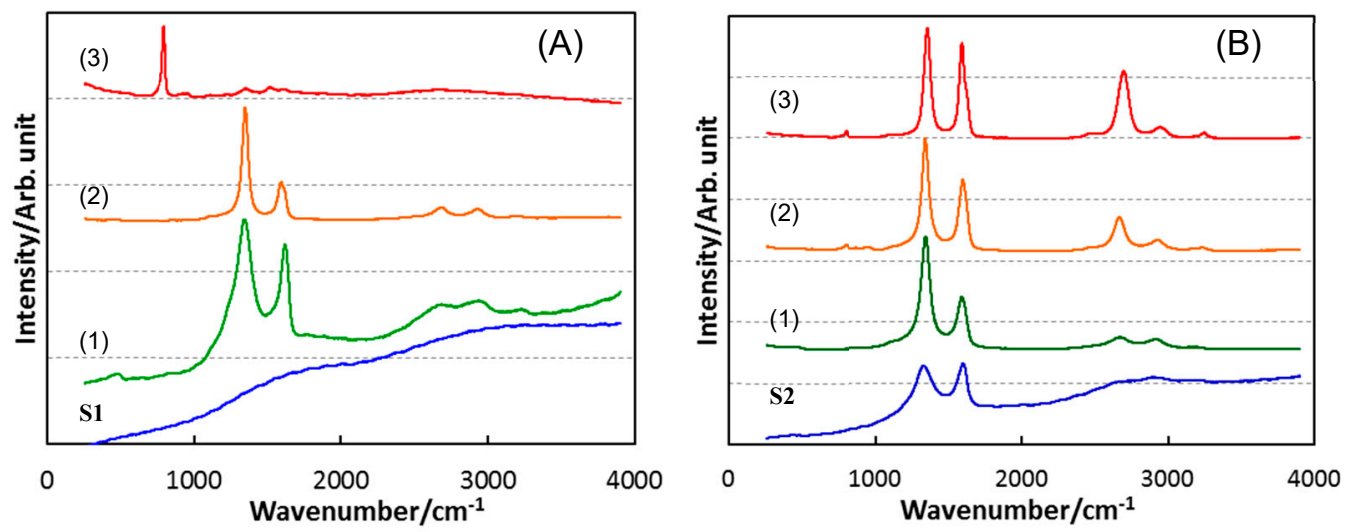

Figure 11. Raman spectra for SQ-derived S1 and S2 synthesized by pyrolysis at $800{ }^{\circ} \mathrm{C}$, and those after subsequent heat treatment at (1) 1400, (2) 1600 and (3) $1800^{\circ} \mathrm{C}$. Polymeric precursors: (A) VH-SQ and (B) St-H-SQ. 
The S1 synthesized by pyrolysis at $800{ }^{\circ} \mathrm{C}$ of VH-SQ was amorphous SiOC single phase, while $\mathrm{S} 2$ was a binary composite of amorphous $\mathrm{SiO}_{2}$ and amorphous/graphitic carbon. The phase separation and crystallization pathway up to $1400-1600{ }^{\circ} \mathrm{C}$ observed in the present study was different from that previously suggested for polymer-derived amorphous $\mathrm{SiOC}$ materials as expressed by Equations (1)-(3) [9-12]. Regardless of carbon content in terms of stoichiometric $\mathrm{S} 1\left(\mathrm{SiO}_{2(1-x)} \mathrm{C}_{\mathrm{x}}\right)$ or $\mathrm{S} 2\left(\mathrm{SiO}_{2(1-x)} \mathrm{C}_{\mathrm{x}}+\mathrm{yC}\right)$, the dominant pathway could be expressed by the following reactions: phase separation to amorphous/graphitic carbon and amorphous $\mathrm{SiO}_{2}$ (Equation (5)), then subsequent $\beta$-SiC crystallization via carbothermal reduction of $\mathrm{SiO}_{2}$ (Equation (2)) to afford binary $\beta$-SiC and amorphous $\mathrm{SiO}_{2}$ (Equation (6)).

$$
\begin{gathered}
\mathrm{xSiO}_{2}(\mathrm{a})+\mathrm{yC}(\mathrm{a} / \mathrm{gra}) \\
(\mathrm{x}-\mathrm{y} / 3) \mathrm{SiO}_{2}(\mathrm{a})+\mathrm{ySiC}(\beta)+2 \mathrm{y} / 3 \mathrm{CO}(\mathrm{g}) \uparrow \\
2 \mathrm{SiO}_{2}(\mathrm{a})+\mathrm{SiC}(\beta) \rightarrow 3 \mathrm{SiO}(\mathrm{g}) \uparrow+\mathrm{CO}(\mathrm{g}) \uparrow \\
(\mathrm{y}-(\mathrm{x}-\mathrm{y} / 3) / 2) \mathrm{SiC}(\beta)+3(\mathrm{x}-\mathrm{y} / 3) / 2 \mathrm{SiO}(\mathrm{g}) \uparrow+(\mathrm{x}-\mathrm{y} / 3) / 2 \mathrm{CO}(\mathrm{g}) \uparrow
\end{gathered}
$$

The VH-SQ-derived S1 was found to keep an amorphous state up to $1400{ }^{\circ} \mathrm{C}$. This enhanced thermal stability could be achieved by the phase separation (Equation (5)) associated with the local structure rearrangement from $\mathrm{SiO}_{2-x} \mathrm{C}_{\mathrm{x}}(\mathrm{x}=1,2)$ to carbon-free $\mathrm{SiO}_{4}$ tetrahedral prior to the formation of $\mathrm{SiC}_{4}$ units, which are essential for the nucleation and crystallization of $\beta$-SiC.

On the other hand, in the case of the St-H-SQ-derived S2 having excess carbon, the initial phase separation (Equation (5)) had already started during pyrolysis up to $800^{\circ} \mathrm{C}$, which could lead to $\beta$-SiC crystallization below $1400^{\circ} \mathrm{C}$.

Further heat treatment above $1400{ }^{\circ} \mathrm{C}$ of the SQ-derived SiOC materials led to apparent weight loss and a remarkable decrease in oxygen content (Table 1, Figure 12a,b). This was mainly the result of a thermodynamically favorable reaction between $\mathrm{SiO}_{2}$ and $\mathrm{SiC}$, which yielded gaseous $\mathrm{SiO}$ and $\mathrm{CO}$ (Equation (7)) [23]. The amorphous $\mathrm{SiO}_{2}$ in the $\mathrm{S} 1$ could be spent out to afford single-phase $\beta$-SiC by heat treatment up to $1800{ }^{\circ} \mathrm{C}$, while this reaction in the $\mathrm{S} 2$ almost completed at $1600{ }^{\circ} \mathrm{C}$. As a result, the final $1800^{\circ} \mathrm{C}$ heat-treated product was $\beta$-SiC with free carbon.



(a)



(b)

Figure 12. Thermal behaviors of VH-SQ-derived S1 and St-H-SQ-derived S2 during heat treatment up to $1800{ }^{\circ} \mathrm{C}$ in Ar. (a) Chemical composition changes and (b) ceramic yields.

\section{Summary}

In this study, silsesquioxane (SQ) derivatives possessing intramolecular $\mathrm{H}_{2} \mathrm{C}=\mathrm{CH}$ - groups and $\mathrm{Si}-\mathrm{H}$ groups were designed and synthesized as precursors for stoichiometric amorphous $\mathrm{SiO}_{2(1-x)} \mathrm{C}_{x}$ with relatively high carbon content $(x>0.15)$. Chemical structures and pyrolysis behaviors of the 
SQ derivatives, as well as thermal behaviors up to $1800^{\circ} \mathrm{C}$ in $\mathrm{Ar}$ of the SQ-derived amorphous SiOC materials, were investigated. The results can be summarized as follows:

(1) ATR-IR and ${ }^{29}$ Si-NMR spectroscopic analyses revealed that the SQ derivatives VH-SQ ( $R=$ vinyl) and St-H-SQ ( $\mathrm{R}=$ stylyl) were successfully synthesized through the conventional sol-gel route using $\mathrm{R}-\mathrm{Si}(\mathrm{OMe})_{3}, \mathrm{H}-\mathrm{Si}(\mathrm{OEt})_{3}$ and $\left(\mathrm{H}-\mathrm{Si}(\mathrm{Me})_{2}\right)_{2} \mathrm{O}$ as starting compounds.

(2) The simultaneous TG-MS analyses showed that, under an inert atmosphere, thermally induced cross-linking via hydrosilylation and demethanation was efficiently achieved. The resulting ceramic yields after heating VH-SQ and St-H-SQ to $1000{ }^{\circ} \mathrm{C}$ were $82 \%$ and $88 \%$, respectively.

(3) Besides of the high ceramic yield, the in-situ cross-linking of VH-SQ led to suppressing the evolution of gaseous species that originated from hydrocarbon substituents up to $800^{\circ} \mathrm{C}$, leading to the formation of amorphous SiOC (labeled as S1) with a desired composition close to the stoichiometric $\mathrm{SiO}_{2(1-x)} \mathrm{C}_{\mathrm{x}}(\mathrm{x}=$ ca. 0.3).

(4) By replacing the vinyl group with the styryl group, the carbon content in the amorphous SiOC successfully increased to afford $\mathrm{SiO}_{0.9} \mathrm{C}_{2.0} \mathrm{H}_{0.8}$ with excess carbon (labeled as $\mathrm{S} 2$ ).

(5) Heat treatment up to $1800{ }^{\circ} \mathrm{C}$ in Ar of the amorphous SiOC materials revealed that, regardless of carbon content (in terms of stoichiometric S1 or S2 having excess carbon), the dominant pathway for $\beta$-SiC crystallization could be expressed by the following reactions: phase separation to amorphous/graphitic carbon and amorphous $\mathrm{SiO}_{2}$, followed by $\beta$-SiC crystallization via carbothermal reduction of $\mathrm{SiO}_{2}$.

(6) The VH-SQ-derived S1 was found to hold an amorphous state up to $1400{ }^{\circ} \mathrm{C}$. This enhanced thermal stability could be achieved by the phase separation associated with the local structure rearrangement from $\mathrm{SiO}_{2-\mathrm{x}} \mathrm{C}_{\mathrm{x}}(\mathrm{x}=1,2)$ to carbon-free $\mathrm{SiO}_{4}$ tetrahedral prior to the formation of $\mathrm{SiC}_{4}$ units essential for the nucleation and crystallization of $\beta$-SiC.

(7) Further heat treatment above $1400{ }^{\circ} \mathrm{C}$ of the SQ-derived SiOC materials led to large weight loss and a remarkable decrease in oxygen content, which could be due to the thermodynamically favorable reaction of $\mathrm{SiO}_{2}$ with $\mathrm{SiC}$ to yield gaseous $\mathrm{SiO}$ and $\mathrm{CO}$.

(8) The VH-SQ was found to be a useful precursor for synthesizing amorphous SiOC with enhanced thermal stability. However, for the formation of $\beta-\mathrm{SiC}-\mathrm{SiO}_{2}$ nanocomposite having a higher fraction of $\beta$-SiC nanocrystallites, it is important to facilitate the nucleation of $\mathrm{SiC}$ prior to phase separation to amorphous/graphitic carbon and amorphous $\mathrm{SiO}_{2}$. Currently, further study of the relationship between the chemical state of carbon and $\mathrm{SiC}$ nucleation within the amorphous $\mathrm{SiOC}$, as well as heat treatment conditions to facilitate $\mathrm{SiC}$ nucleation, are in progress.

Author Contributions: Conceptualization, Y.H. and Y.I.; Data curation, S.H. and Y.D.; Formal analysis, T.F. and S.H.; Investigation, Y.I.; Methodology, Y.I.; Project administration, Y.H. and Y.I.; Resources, Y.I.; Supervision, Y.I.; Validation, T.F. and Y.D.; Visualization, Y.I. and Y.I.; Writing-original draft, Y.I. and Y.I.; Writing-review \& editing, Y.I.

Funding: This research received no external funding.

Conflicts of Interest: The authors declare no conflict of interest.

\section{References}

1. Díaz, U.; Corma, A. Organic-Inorganic Hybrid Materials: Multi-Functional Solids for Multi-Step Reaction Processes. Chem 2018, 24, 3944-3958. [CrossRef] [PubMed]

2. Mir, S.H.; Nagahara, L.A.; Thundat, T.; Mokarian-Tabari, P.; Furukawa, H.; Khosla, A. Review-Organic-Inorganic Hybrid Functional Materials: An Integrated Platform for Applied Technologies. J. Electrochem. Soc. 2018, 165, B3137-B3156. [CrossRef]

3. Toagosei Co., Ltd. Organosilicon Compounds which have Oxetanyl Groups, and a Method for the Production and Curable Compositions of the Same. Patent No JP5454762, 26 March 2014.

4. Kimoto, Y.; Fujita, T.; Furuta, N.; Kitamura, A.; Suzuki, H. Development of Space-Qualified Photocurable-Silsesquioxane-Coated Polyimide Films. J. Spacecr. Rocket. 2016, 53, 1028. [CrossRef] 
5. Toagosei Co., Ltd. Composition for Organic Semiconductor Insulating Films, and Organic Semiconductor Insulating Film. Patent No JP5704256, 22 April 2015.

6. Toagosei Co., Ltd. Silicon-Containing Polymer Compound, Manufacturing Method of the same, Heat-Resistant Resin Composition, and Heat Resistant Coating. Patent No JP5601212, 8 October 2014.

7. Blum, Y.D.; MacQueen, D.B.; Kleebe, H.-J. Synthesis and characterization of carbon-enriched silicon oxycarbides. J. Eur. Ceram. Soc. 2005, 25, 143-149. [CrossRef]

8. Colombo, P.; Mera, G.; Riedel, R.; Soraru, G.D. Polymer-derived ceramics: 40 years of research and innovation in advanced ceramics. J. Am. Ceram. Soc. 2010, 93, 1805-1837. [CrossRef]

9. Saha, A.; Raj, R. Crystallization Maps for SiCO Amorphous Ceramics. J. Am. Ceram. Soc. 2007, 90, 578-583. [CrossRef]

10. Kleebe, H.-J.; Turquat, C.; Soraru, G.D. Phase Separation in an SiCO Glass Studied by Transmission Electron Microscopy and Electron Energy-Loss Spectroscopy. J. Am. Ceram. Soc. 2001, 84, 1073-1080. [CrossRef]

11. Stabler, C.; Roth, F.; Narisawa, M.; Schliephake, D.; Heilmaier, M.; Lauterbach, S.; Kleebe, H.-J.; Riedel, R.; Ionescu, E. High-temperature creep behavior of a SiOC glass ceramic free of segregated carbon. J. Eur. Ceram. Soc. 2016, 35, 3747-3753. [CrossRef]

12. Stabler, C.; Reitz, A.; Stein, P.; Albert, B.; Riedel, R.; Ionescu, E. Thermal Properties of SiOC Ceramics at Elevated Temperatures. Materials 2018, 11, 279. [CrossRef] [PubMed]

13. Williams, E.A. Chapter 8, NMR Spectroscopy of Organosilicon Compounds. In The Chemistry of Organic Silicon Compounds Part 1; Patai, S., Rappoport, Z., Eds.; John Wiley \& Sons Ltd.: Hoboken, NJ, USA, 1989; pp. 511-554.

14. Pippel, E.; Lichtenberger, O.; Woltersdorf, J. Identification of silicon oxycarbide bonding in Si-C-O-glasses by EELS. J. Mater. Sci. Lett. 2000, 19, 2059-2060. [CrossRef]

15. Wei, Q.; Pippel, E.; Woltersdorf, J.; Scheffler, M.; Greil, P. Interfacial SiC formation in polysiloxane-derived Si-O-C ceramics. Mater. Chem. Phys. 2002, 73, 281-289. [CrossRef]

16. Savchenko, D.; Vasin, A.; Muto, S.; Kalabukhova, E.; Nazarov, A. EPR Study of Porous Si:C and $\mathrm{SiO}_{2}: \mathrm{C}$ Layers. Phys. Status Solidi B 2018, 255, 1700559. [CrossRef]

17. Ferrari, A.C.; Robertson, J. Interpretation of Raman spectra of disordered and amorphous carbon. Phys. Rev. B 2000, 61, 14095-14107. [CrossRef]

18. Pimenta, M.A.; Dresselhaus, G.; Dresselhaus, M.S.; Cancado, L.G.; Jorioa, A.; Saitoe, R. Studying Disorder in Graphite-Based Systems by Raman Spectroscopy. Phys. Chem. Chem. Phys. 2007, 9, 1276-1291. [CrossRef] [PubMed]

19. Nakashima, S.; Higashihira, M.; Maeda, K.; Tanaka, H. Raman Scattering Characterization of Polytype in Silicon Carbide Ceramics: Comparison with X-ray Diffraction. J. Am. Ceram. Soc. 2003, 86, 823-829. [CrossRef]

20. Mutin, P.H. Role of Redistribution Reactions in the Polymer Route to Silicon-Carbon-Oxygen Ceramics. J. Am. Ceram. Soc. 2002, 85, 1185-1189. [CrossRef]

21. Widgeon, S.J.; Sen, S.; Mera, G.; Ionescu, E.; Riedel, R.; Navrotsky, A. ${ }^{29}$ Si and ${ }^{13}$ C Solid-State NMR Spectroscopic Study of Nanometer-Scale Structure and Mass Fractal Characteristics of Amorphous Polymer Derived Silicon Oxycarbide Ceramics. Chem. Mater. 2010, 22, 6221-6228. [CrossRef]

22. Ohyanagi, M.; Imai, T.; Toyofuku, N.; Nakagawa, D.; Munir, Z.A. Microscopic and Spectroscopic Characterization of Stacking-Sequence Disordered SiC. J. Am. Ceram. Soc. 2015, 98, 50-56. [CrossRef]

23. Filsinger, D.H.; Bourrie, D.B. Silica to Silicon: Key Carbothermic Reactions and Kinetics. J. Am. Ceram. Soc. 1990, 73, 1726-1732. [CrossRef]

(C) 2019 by the authors. Licensee MDPI, Basel, Switzerland. This article is an open access article distributed under the terms and conditions of the Creative Commons Attribution (CC BY) license (http://creativecommons.org/licenses/by/4.0/). 